IRA-International Journal of Management \& Social Sciences

ISSN 2455-2267; Vol.08, Issue 02 (August 2017)

Pg. no. 221-226

Institute of Research Advances

http://research-advances.org/index.php/RAJMSS

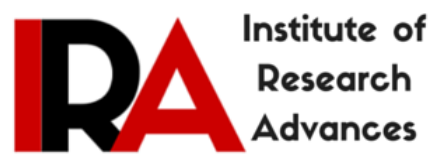

Research

Advances

\title{
The Peculiarities of Family Doctors Retraining in Georgia
}

Lela Murusidze $^{1}$, Irine Zarnadze ${ }^{2}$, Shalva Zarnadze ${ }^{3}$, Tamar Bakradze ${ }^{4}$, Jilda Cheishvili ${ }^{5 \#}$

${ }_{1,2,3,4,5}$ Department Of Public Health, Health Care Management, Policy and Economy

Tbilisi State Medical University, Tbilisi, Georgia.

\# corresponding author.

Type of Review: Peer Reviewed.

DOI: http://dx.doi.org/10.21013/jmss.v8.n2.p10

\section{How to cite this paper:}

Murusidze, L., Zarnadze, I., Zarnadze, S., Bakradze, T., Cheishvili, J. (2017). The Peculiarities of Family Doctors Retraining in Georgia. IRA-International Journal of Management \& Social Sciences (ISSN 2455-2267), 8(2), 221-226. doi:http://dx.doi.org/10.21013/jmss.v8.n2.p10

(C) Institute of Research Advances.

\section{(c) $\mathrm{EY}$-NC}

This work is licensed under a Creative Commons Attribution-Non Commercial 4.0 International License subject to proper citation to the publication source of the work.

Disclaimer: The scholarly papers as reviewed and published by the Institute of Research Advances (IRA) are the views and opinions of their respective authors and are not the views or opinions of the IRA. The IRA disclaims of any harm or loss caused due to the published content to any party.

Institute of Research Advances is an institutional publisher member of Publishers Inter Linking Association Inc. (PILA-CrossRef), USA. The institute is an institutional signatory to the Budapest Open Access Initiative, Hungary advocating the open access of scientific and scholarly knowledge. The Institute is a registered content provider under Open Access Initiative Protocol for Metadata Harvesting (OAI-PMH).

The journal is indexed \& included in WorldCat Discovery Service (USA), CrossRef Metadata Search (USA), WorldCat (USA), OCLC (USA), Open J-Gate (India), EZB (Germany) Scilit (Switzerland), Airiti (China), Bielefeld Academic Search Engine (BASE) of Bielefeld University, Germany, PKP Index of Simon Fraser University, Canada. 


\begin{abstract}
Working out of the human resources development policy and long-term plan, funding of critical specialties and employment of sought-after experts in coastal and mountainous regions, coordination and standardization of continuing and medical education are necessary. Geographical and financial availability of the first healthcare services, create the adequate conditions of the first healthcare team which one consists: appropriate equipment and physical infrastructure, medical documents, to acknowledge the necessity of team working in healthcare system and define the proper contract obligations for doctors, for the reason of medical service improvement quality in providing the Disease Control national recommendations and standards availability for regional doctors, encourage the audit system, spread information about the reform of Georgian healthcare in populations and healthcare professionals, encourage patient's education, check the teaching programs of doctors retraining on which foundation will be able to create better conditions for practical skills.
\end{abstract}

Our country must encourage to hold some priority scientific researches as in the field of state as in international grant program. Above-mentioned can be implemented by the active collaboration with USA and European disease control leading medical schools or universities, scientific funds and other international partner organizations.

Keywords: Family doctors, Retraining

\title{
Introduction
}

Healthcare human resources play a key role in effective functioning of the country's healthcare system, in maintaining, resuscitating and enhancing the population health.

One of the top items on the country development priority list in modern era is developing healthcare human resources and proving high quality medical services and education. New discoveries and technology advancement in medicine, reemerging and fast-growing problems, healthcare system reform and stakeholder/patient high demand require equipping doctors with skills and education based on scientific research meeting the modern standards, based on curriculum adapted to modern demands and setting up adequate institutionalized potential for the cause.

Medical education experienced cardinal changes in the 21-st century, the international, medical organizations (WFME, ASME, IAMSE, IMI, MEDINE, UNESCO, WHO, WMA) have contributed to shift from mere quality provision to constant quality enhancement in medical education and healthcare human resources paradigm. One of the vital objectives of the Georgian healthcare system reform is the development of modern primary healthcare system, providing population with basic medical services. According to the "Medical Service Model" developed by the Ministry of Health, Labor and Social affairs of Georgia in 2006 "The provider of medical services at the primary healthcare level is a family doctor, who is skilled enough to identify and manage most of the population basic medical needs according to the principles of family medicine. Family doctor closely collaborates with the primary healthcare team members, nurses and midwives".

It hasn't been only Georgia that expressed the desire of making a transition from a polyclinic system, characteristic of the primary healthcare Semashko model, to family medicine. Most countries with transitive economic systems have undergone the same processes with more or less success. All of them faced the challenge of inadequate education and lack of professionalism in personnel, necessitating the need of retraining of narrow specialists working in the primary healthcare system into family doctors.

\section{Way from a general practitioner to a family doctor- what is the difference?}

General practitioners as medical professionals emerged in Europe and the United States in the 18-th century .The term- General practitioner first occurred in Britain at the beginning of the 19-th century.

In the era of general practice advancement, the idea of renaming it in, family medicine" occurred.

Most authors today use the term - General practitioner/Family doctor with the identical meaning. 
The practice of General practitioner/Family doctor requires certain knowledge referred as "family medicine", "knowledge" here implies not purely theoretical knowledge, but certain practical skills and techniques as well.

Since the first days of Georgia's independence in 1991, the government acknowledged the existence of two independent, yet correlative problems in the healthcare sector. First problem was the mortality rate caused by the chronic illnesses, especially the cardio-vascular diseases, by the end of 1990, $70 \%$ of the total mortality rate was caused by the pathologies of cardiovascular systems. Diseases were caused by the economic downturn, unemployment, etc. The second problem was the lack of doctors and nurses possessing competencies identifying and managing chronic and other wide-spread diseases and primary and secondary prevention strategies in society/ community. There had been numerous medical specialists in the country and yet the shortage of competent, general practitioners had been obvious. The budget cut in healthcare caused insufficient financial support.

The solution of the above mentioned 2 interrelated problems by the Georgian healthcare policies have been preceded by the acknowledgement of 2 facts about the primary medicine doctors. First- the utilization of primary healthcare system doctors contributes to cost-effectiveness of healthcare system, second- since the primary healthcare doctors are employed at the community centers and possess the skills of chronic disease screening and management, they can easily substitute the specialists with such responsibilities. The government of Georgia acknowledges that medical services will be more productive due to the primary healthcare system.

According to the "Universal European healthcare" data-base the annual, average number of outpatients in Georgia had been 2:1in 2008, which is a very little number and less compared to all the other country rates.

That is the reason why the intensive program of retraining of general practitioners in family doctors had been initiated. The strategy (known as the national, master plan) had been approved by the European and American donor governments and international monetary agencies.

The doctor retraining is different in developing countries, from that of the developed countries. In many cases some hindrances and obstacles are observed in the education sector, resulting in poor service provision. The common obstacles include, but aren't limited to: lack of studying resources, medical technologies, communication, healthcare information management, security, transportation material-technical base, inadequate nursing services and infrastructure management.

Ministry of Health, Labor and Social Affairs of Georgia with the collaboration of Department of International Development (DFID) introduced a 940- hour educational program retraining general practitioners into family doctors in 1998. The Center for International Health engaged in family doctor retraining program with the support of the United States Agency for International Development grant and with the support of the US International Union of Healthcare in 1999. Partnership program of Mtskheta-Mtianeti healthcare regional department was financed with the grants (United States Agency for International Development, the US International Union of Healthcare, "Partners for Healthcare" grant program for the Commonwealth of Independent States) and the first regional center for family medicine training was set up outside the capital.

The educational program had been accredited by the continuous professional development council.

The family doctor and nurses retraining pilot program had been implemented in 1997-1998 in Georgia with the support from the British Know How Fond.

The process of retraining polycninic network doctors into family doctors was initiated in Geoergia in 1999. 940hour family doctor retraining program had been carried out in collaboration with (Center for International Health) and local healthcare entities through the integration of curriculum, seminars and practical studies. 1336 family doctors had been retrained by 2009 , providing the fact that 2106 doctors had been in demand countrywide according to the "Medical serive model".

It's a commonly recognized fact that general practice or family medicine is the core to primary healthcare, since it can guarantee available, effctive and high qulaity primary medical services. Family medicine doesn't relate only to cerain parts of healthcare but serves the needs of population in general without disciminatiingon age and gender basis.So the interest of reserching the practical works of this trend and evaluating its achivement is only natural. 
Research objectives: Researching the specifics of family medicine retraining in Georgia and countries with transitive economic systems, studying the processes of family doctor retraining and evaluting the obtained results, numerical and quality analysis offamily doctors trainings, observing the work of trained family doctors and assesing their success.

Research methods and material : systemic analysis method and survey research wasutilized together with document analysis and secondary information reserch methods. The project reports relating to the family medicine implemantion in Georgia sponsored by the state, international and bilateral donors will be analysed for numerical and quality evaluation of family doctor trainings in Georgia.

Research results and analysis: Healthcare system reform is under way in Georgia, which implies the development of basic healthcare packages, decentralization of healthcare management, refining primary healthcare and reforming hospital sector, making the medical service provider choices optional for patient, implementation of high quality technologies and medical services.

Updated recommendation was provided by the International Labor Organization in 2004 regarding "Human resources development: teaching, training and lifelong education" (\#195). Updated version of the international labor standards was issued in 2009.

World Health Organization (WHO) provided recommendation on developing human resources with high qualification.

Developing high medical standards is defined as one of strategic directions of the healthcare reform modernization process in Georgia, the core component of which is providing medical market with qualified and motivated medical staff.

The issue of professionalism has become of vital importance alongside with the equal access to healthcare entities in healthcare sphere in recent years in Georgia . The UN report on healthcare situation in Georgia states that "One of the biggest hurdles in providing effective services in healthcare system within the clinical system is the "outdated methods and insufficient knowledge and qualification of the medical staff'"

Doctor professionalism has been targeted and questioned widely among the media sources and professional circles recently. It's important for the educational medical institutions to identify the ways of meeting the challenges in healthcare system and setting up strategies for overcoming the hindrances in the sphere.

Healthcare is of the biggest and fast-growing industries in the world. According to the UN International Standard Industrial Classification of All Economic activities (ISIC) healthcare is composed of 3 trends: hospital activities, medical and dental practices and other issues relating healthcare.

Official, statistical data on human resources in Georgia is available at the websites and publications of Ministry of Labor, Health and Social Affairs of Georgia, National Center for Disease Control and Public Health of Georgia, National Statistics Office in Georgia.

In managing the human resources in healthcare system, it's vital to disseminate the doctors in a proportional manner not only based on geographical area, but based on specialties as well.

The recommended proportion of doctors and nurses by the World Health Organization is 1:4. The proportion of doctors and nurses complies with the standard in developed counties. The biggest proportion rate is shown in Denmark $(1: 5,6)$ and Norway $(1: 4,7)(\mathrm{NCDC}, 2010)$, The proportion rate is 1:1 in Georgia the proportion rates vary according to regions .

National specifics of the Georgian healthcare human resources sphere must be underpinned to the human resources development and education policy strategic dimension. Each country introduces effective approaches and innovations in education policy based on its healthcare needs, which ultimately contributes to preparing human resources with high qualification and knowledge at the national level. 
The information on human resources in healthcare, deficiency or redundancy of medical staff in the country must be the one of the core factors in human resources development, designing educational policies and growth or downsize of educational medical institution potential.

Before gaining independence, there had been only a sole educational institution with medical profile in Georgia (Tbilisi State Medical Institute), which was providing the labor market with 600-800 graduates annually. The rate of graduates had been 30,09 in regards to 10000 population rate in Georgia in 1980, which was twice as much compared to the Soviet Union average rate, it had been - 52,52 in regards to population rate of 10000 in 1988, the rate was downsized to 37,03 in 1992 . The private Educational Institutions had been founded in the country since 1995, the number of educational institutions with medical programs reached 73 in 2004, 69 out of which had been private and 4 -state, 22 educational institutions had been located in Tbilisi, with 15000-students and 3000-graduates. The demand for doctor graduates had been defined as- 350 and 1400- in case of nurse graduates by the national healthcare strategy of Georgia considering the average European rate.

Medical Educational Institutions have the potential of producing high qualification medical staff with who can be actively involved in continuous educational processes in collaboration with the leading medical schools and centers in the US and Europe.

The fact that family doctors are general practitioners, doesn't necessarily mean that they all have identical knowledge and skills, due to the specialty specifics and trainings, family doctors may vary in knowledge and skill range. Not only do the family doctors have to dismantle barriers among the clinical disciplines, but often have to go far beyond the medical problems and face the social issues.

Each country introduces effective approaches and innovations in education policy based on the healthcare needs, which ultimately contributes to training of highly qualified human resources at the national level. The country possesses the sufficient human resource to become the leading country in the Caucasian region.

The state policy objective in healthcare sphere is increasing the life-expectancy of Georgian population, reducing mother and child mortality rates, advancing health and life quality due to the high standards of medical services and by guaranteeing universal access to modern medical treatments and by formulating a flexible, management system.

Conclusion: Developing human resources advancement long term plans, financing rare specialties and their employment at the coastal territories and high mountainous regions, coordination and standardization of continuous medical education. Identifying the geographical and financial barriers to the primary healthcare and making political decisions for their solutions, creating adequate conditions for the effective functioning of primary healthcare teams that comprises proper equipment and infrastructure, medical documentation, recognition of team work in the primary healthcare by the medical stakeholders and defining proper contractual duties and obligations for doctors. Carrying out the following activities with the medical services quality advancement in mind: supporting the provision of regional doctors with national recommendations and standards of disease control, audit system introduction, dissemination of the information on family medicine model and Georgian healthcare reform in Georgia among the population and healthcare professionals, contributing to the patient education, supporting continuous education based on the needs revealed in assessment, reviewing the family doctor retraining program resulting in better methods for practical skills development.

Governmental support for doing the priority scientific researches within the state and international grants, in collaboration with the US and European Disease Control centers, leads schools/universities, scientific foundations and other international partnership organizations. 


\section{References:}

[1] Ministry of Health, Labor and Social Affairs of Georgia, National Center for Disease Control and Public Health of Georgia (NCDC), World Bank and United Nations Statistical data bases.

[2] Ministry of Health, Labor and Social Affairs of Georgia report www.moh.gov.ge

[3] Statistical reference book, Healthcare

[4] O. Gerzmava "Public Health and Management", 2008

[5] Caucasus Medical Network. www.medgeo.net.

[6] Adams, T, Garden, A. (2006) What influences medical school choice? J.Medical Teacher. 28:83-85.

[7] Barry D, Cyran E, Anderson RJ. (2000). Common issues in medical professionalism: Room to grow. Am J Med 108:136-142.

[8] World Health Organization.(2010) Workload Indicators of Staffing Need (WISN).

[9] Martina Pelly, Views of the pioneer GPS and status quo of the PHC reform in Georgia, - 2006, December.

[10] Evaluation of Specialty Doctors Retraining into Medical Doctors and General Practitioner Nurses Retraining Program - Family Medicine Professional's report, February, 2006

[11] David Simpson, Tamar Shanidze- EU TACIS Program for Georgia, European Union support for Georgia's Primary Healthcare, 2006.

[12] Assessment of Family Doctor Works in Adjara, Imreti Regions, financed by the European Union, 2006.

[13] Assessment of Family Doctor Works in Kakheti Region, financed by the European Union, 2007.

[14] Assessment of Family Doctor Works in Samegrelo and Lower Kartli Regions, financed by the European Union, 2008

[15] Specialty Doctors Retraining into Medical Doctors Study Program (Second revision) 2006.http://www.gfma.ge/documents/Retraining\%20FP-GEO\%202006Final.pdf

[16] Medical Service Model - Ministry of Health, Labor and Social Affairs of Georgia, 2006, http://www.moh.gov.ge/ge_pdf/ modeli.pdf

[17] Minister of Health, Labor and Social Affairs of Georgia Decree N 103/O "Department of International Development (DFID) and Georgia mutual project on "Primary Healthcare Development in Georgia" "-(15.04.2002).

[18] Master Plan of Primary Healthcare Development in Georgia- Ministry of Health, Labor and Social Affairs of Georgia 2007. http://www.moh.gov.ge/ge_pdf/jr/phc_n.pdf

[19] Assesment of Georgian Healthcare efficiency, brief report- World Health Organization regional Office -2009. http://www.moh.gov.ge/ge_pdf/shefaseba/sh.pdf

[20] I.Karosanidze, T.Gabunia, V.Doborjginidze- Family Medicine, Tbilisi, 2001

[21] Atun R., et.al. - Moldova Health system review. - Health Systems in Transition, Vol. 10, No 5, 2008. http://www.euro.who.int/ Document/E91756.pdf

[22] European Health for All database (HFA-DB).WHO, Regional Office for Europe. http://www.euro.who.int/HFADB (last viewed on February 24, 2010)

[23] Hakobyan T., et.al. - Armenia Health system review. - Health Systems in Transition, Vol. 8, No 6, 2006. http://www.euro.who.int/Document/E89732.pdf

[24] Koppel A., et.al. - Estonia Health system review. - Health Systems in Transition, Vol. 10, No 1, 2008. http://www.euro.who.int/Document/E91372.pdf

[25] Taylor R.B. - Family Medicine: Principles and Practice (Sixth Edition). - Springer-Verlag, 2003.

[26] Tragakes E., et.al. - Latvia Health system review. - Health Systems in Transition, Vol. 10, No 2 , 2008. http://www.euro.who.int/Document/E91375.pdf

[27] Vladescu C., Scintee G., Olsavszky V. - Romania Health system review. - Health Systems in Transition, Vol. 10, No 3, 2008. http://www.euro.who.int/Document/E91689.pdf

[28] Sloane P.D., et.al. - Essentials of Family Medicine (Fifth Edition). - Lippincott Williams \& Wilkins, 2007.

[29] Martina Pelly, Views of the pioneer GPS and status quo of the PHC reform in Georgia, - 2006, December. 